\title{
Chapter 19 \\ Determining the Precipitation Intensity Threshold of Debris Flood Occurrence
}

\author{
Mohammad Ebrahim Banihabib and Mitra Tanhapour
}

\begin{abstract}
In this chapter, the precipitation threshold at which debris floods occur was evaluated experimentally, and the factors that influence debris flood occurrence, including the bed slope, sediment layer thickness, sediment grain size, length of alluvial flow direction, precipitation intensity, and time of debris flood occurrence, were examined. The impacts of these factors on debris flood initiation were investigated through dimensional analysis. Then, a method was developed to estimate the precipitation intensity threshold based on a set of laboratory tests. Furthermore, different methods for determining the precipitation intensity threshold at which debris floods are initiated were assessed and discussed. The results of the experiments showed that the effect of the sediment layer thickness on debris flood occurrence can be ignored. Moreover, by independently evaluating the effect of each factor on debris flood occurrence, it was found that the sediment length and average diameter of sediments are influential to debris flood initiation. The results of this research provide a better understanding of debris flood mechanisms and occurrence thresholds of debris floods and can be employed to prepare a forecasting model.
\end{abstract}

Keywords Debris floods - Dimensional analysis - Precipitation intensity thresholds - Sediment layer thickness

\footnotetext{
M. E. Banihabib ( $\square)$

Department of Water Engineering, University of Tehran, Abouraihan Campus, Tehran, Iran e-mail: banihabib@ut.ac.ir

M. Tanhapour

Hydraulic Structure, University of Tehran, Abouraihan Campus, Tehran, Iran

e-mail: mitratanhapour@ut.ac.ir

(C) The Author(s) 2022

T. Sumi et al. (eds.), Wadi Flash Floods, Natural Disaster Science and Mitigation

Engineering: DPRI Reports, https://doi.org/10.1007/978-981-16-2904-4_19
} 


\subsection{Introduction}

Heavy precipitation events lead to flash floods in mountainous areas. Flash floods generally move quickly in rivers due to intensive precipitation in river basins and can trigger landslides suddenly due to heavy rainfall in small basins (He et al. $2018 \mathrm{a}, \mathrm{b})$. Intensive rainfall can usually produce flash floods and debris floods. The type of event (debris flood or flash flood) depends on different factors, e.g., the hydrological, geotechnical, and geomorphological characteristics of steep slopes, material sources, the volume of available sediments, and characteristics related to the frequency and magnitude of precipitation events (Borga et al. 2014).

Debris floods are common phenomena in many areas worldwide (Mangeney et al. 2010; Banihabib and Nazarieh 2019; He et al. 2018a, b). Debris floods are the main factor affecting erosion and sedimentation in riverbeds or channels and create many environmental hazards (Berger et al. 2011). These flows generally consist of granular materials and concentrated compositions of water and sediments (Banihabib and Forghani 2017; Banihabib and Masumi 1999). The sediment concentrations of debris floods vary in different circumstances, from loose deposits to flows. There is a wide range of debris flood sediment concentrations, which are reported to range from 2 percent by volume to 80-90\% (Banihabib et al. 2020; Takahashi 1981; Coussot and Meunier 1996). For typical events, the water content is small, approximately $10-30 \%$. Furthermore, the range of the particle diameters is approximately $10^{-6}$ to $10 \mathrm{~m}$ (Zhuang et al. 2015). These debris flood features make them potentially powerful and disastrous factors due to their abilities to transport large volumes of coarse-grained materials and destroy facilities, infrastructures, and the environment (Hassan-Esfahani and Banihabib 2016; Iverson and Denlinger 2001). The hazards caused by debris floods are enhanced by their sudden occurrences. Therefore, understanding the processes of debris flood occurrences is necessary not only to obtain insights into the mechanisms of debris flood occurrences but also to predict and avoid hazards (Shu et al 2017; Banihabib and Tanhapour 2020). Due to the complexity of the mechanism of these floods and their high speeds, laboratory methods are appropriate tools for studying debris flood initiation processes (Cogan and Gratchev 2019).

Flash floods and debris floods are among the most destructive natural disasters with the highest risk potentials in the world due to their rapid occurrences, very short time intervals from the moments of precipitation initiation to flood generation, and the spatial distributions of their affected areas (Borga et al. 2014; Kotlyakov et al. 2013; Diakakis and Deligiannakis 2017; Ashley and Ashley 2008). According to Barredo's assessments, flash floods caused 49 fatalities per year in Europe on average during the years from 1950 to 2005 (Barredo 2007). Salvati et al. (2010) reported that more than 2204 landslides and debris floods occurred due to precipitation over a period of 59 years (1950-2008) in Italy and caused 4103 fatalities. Furthermore, studies have illustrated that predicting and warning people about flash floods and debris floods are difficult because of the sophisticated processes of their formations, the uncertainty associated with intense and short-term precipitation 
events and the dependency of these types of floods on various physiographic and hydrological factors of river basins (Sun et al. 2012; Diakakis et al. 2020). Therefore, it is indispensable to provide a simple and practical approach for predicting debris floods to detract from the risks and damages caused by them.

Although debris floods often occur due to key factors such as heavy precipitation, abundant sediment, and steep slopes (Jomelli et al. 2015; Banihabib et al. 2020), they can also begin due to landslides, snowmelt, and failure of temporary dams blocking rivers (Procter 2012; Evans et al. 2001). Most previous studies primarily evaluated the influences of one or more specific factors, e.g., bed slope, particle size distribution, and precipitation intensity on debris flood initiation. $\mathrm{Hu}$ et al. (2014) used laboratory flumes to study the effects of discharge and slope on the mechanism of debris flood initiation. They found that the effects of slope on erosion and the volume of flow deposits were greater than the effects of flow discharge (Hu et al. 2014). Pellegrino and Schippa (2018) investigated the impacts of particle concentrations and coarse materials on the triggering of debris floods. Based on experimental evidence, they revealed that the viscous features that comprise the stresses and the volumetric viscidity are affected by coarse materials. Moreover, the flow features are sensitive to variations in solid content and particle size (Pellegrino and Schippa 2018). An empirical equation was proposed by Takahashi (1977). He performed a set of experiments to investigate debris flow occurrence under different discharge flow and bed slope values. According to his proposed equation, the concentration of solid materials was obtained based on the bed slope (Takahashi 1977). Dong et al. (2009) presented an equation to obtain the average volume of sediments in debris flows by collecting data on debris floods that occurred due to the Toraji typhoon (Dong et al. 2009). In another study, Takahashi and Kuang (1986) presented equations for the deposition rate and erosion rate of debris floods. Egashira (1993) evaluated the mechanism of debris floods over an erodible bed and proposed a formula for the bed erosion rate.

Most previous studies did not investigate the influence of altering the sediment layer thicknesses on debris flood occurrence. In the present study, a set of laboratory tests were performed at different sediment thicknesses and bed slopes to estimate the precipitation intensity threshold that triggers debris floods. A key piece of information associated with debris flood warning systems is that all precipitation events cannot produce debris floods. Therefore, it is crucial to determine the precipitation intensity threshold that triggers debris floods. In these laboratory tests, the precipitation intensity and the timing of the debris flood occurrence were measured. Then, using dimensional analysis, empirical equations between precipitation intensity (as the dependent variable) and each dimensionless variable, including bed slope, sediment layer thickness, average grain size, and sediment sample length (as the independent variables), were obtained separately. In addition, different methods for deriving the precipitation intensity threshold of debris floods were discussed in this chapter. Finally, the proposed equation obtained in the present research was compared with the equations obtained in other studies. 


\subsection{Material and Methods}

\subsubsection{Experimental Facilities}

A laboratory flume was used for the tests. Its length, width, and depth were 7.6, 0.3, and $0.25 \mathrm{~m}$, respectively. The laboratory tests were performed in a Plexiglas tilting flume. A gauge was utilized to obtain the slope of the flume, and the gauge could be installed anywhere in the flume. In addition, we applied a rain simulator to produce precipitation over the loose deposit sample. A Casio EX-F1 video camera was used to record the timing of the debris flood occurrences.

\subsubsection{A Theory for Initiating Debris Floods}

Hirano (1997) demonstrated that the critical conditions for debris flood occurrence may be incurred at the thickness of the sediment layer $(D)$ if the shear stress is greater than the shear strength (Fig. 19.1). He noted that debris floods occur if the cumulative precipitation at the concentration time $(T)$ is more than the specified amount (Eq. (19.1)):

$$
R(t, T)=\int_{t-T}^{t} r(t) \mathrm{d}(t) \geq \frac{D K}{L} \tan \theta=R_{c}
$$

where $L$ is the alluvial length, $\theta$ is the bed slope, $R_{c}$ is the precipitation threshold of debris flood initiation, $D$ is the depth of loose materials, $K$ is the hydraulic conductivity, $t$ is the time, and $r(t)$ is the precipitation intensity.

To determine the precipitation threshold of debris flood initiation in Eq. (19.1), $K$ and $D$ must be measured; however, the determination of these factors is difficult under field conditions, and they cannot be determined precisely. Therefore, we tested other available factors to obtain the precipitation threshold of debris flood initiation.

Fig. 19.1 Schematic plan of a slope bed
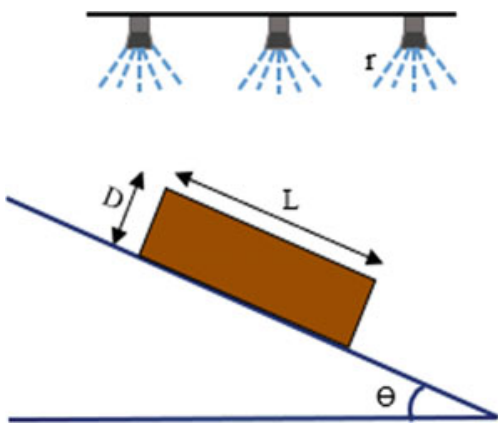


\subsubsection{A Set of Influential Factors}

Hydrological, climatic, and topographic factors are the most important factors that are effective in triggering debris floods (Liang et al. 2012; Chang et al. 2010). Generally, physiographic parameters (e.g., loose material, river length, and steep slopes) and hydrological factors (e.g., antecedent soil moisture, and heavy precipitation) influence debris flood initiation (Banihabib and Tanhapour 2019). The influencing factors and their relevant abbreviations and units are shown in Table 19.1. The grain mean diameter was estimated to be $0.7 \mathrm{~mm}$ using the sediment aggregate curve. The sediment length was $25 \mathrm{~cm}$ (equal to the length of the rain simulator). The layer thickness of the particles ranged from 1 to $3.5 \mathrm{~cm}$. The bed slope was variable between $36^{\circ}$ and $58^{\circ}$ during the tests.

In the current study, the Buckingham theorem was applied to extract the dimensionless factors and to analyze the factors that influenced the occurrence of debris floods. Based on Hirano's research results, the set of factors used in this study was as follows (Eq. (19.2)):

$$
F\left(I, t, d_{50}, \tan \theta, L, D, g\right)=0
$$

Based on the Buckingham theorem, with $\mathrm{N}$ factors and $\mathrm{M}$ main dimensions, we can extract $N-M$ dimensionless factors. If we show dimensionless factors as $\Pi_{1}, \Pi_{2}$, etc., Eq. (19.2) can be rewritten as Eq. (19.3):

$$
F\left(\Pi_{1}, \Pi_{2}, \Pi_{3}, \ldots, \Pi_{N-M}\right)=0
$$

Length and time are the main dimensions of the factors used in this study. Furthermore, the number of repetitive variables must be equal to the number of main dimensions. Moreover, the timing of debris flood occurrences and gravitational acceleration were considered to be repetitive variables. Based on the mentioned explanations, a total of five dimensionless factors were obtained, which are presented in Eqs. (19.4)-(19.8) as follows:

Table 19.1 Factors that influence the occurrence of debris floods

\begin{tabular}{l|l|l}
\hline Factor & Abbreviation & Unit \\
\hline Precipitation intensity & $I$ & Meter per second \\
\hline Time & $t$ & Second \\
\hline Grain mean diameter & $d_{50}$ & Meter \\
\hline Bed slope & $\tan \theta$ & Radian \\
\hline Sediment layer length & $L$ & Meter \\
\hline Sediment layer thickness & $D$ & Meter \\
\hline Gravitational acceleration & $g$ & Meter per second squared \\
\hline
\end{tabular}




$$
\begin{aligned}
& \Pi_{1}=\tan \theta \\
& \Pi_{2}=\frac{\sqrt{g} t}{\sqrt{d_{50}}} \\
& \Pi_{3}=\frac{\sqrt{g} t}{\sqrt{D}} \\
& \Pi_{4}=\frac{\sqrt{g} t}{\sqrt{L}} \\
& \Pi_{5}=\frac{I}{g t}
\end{aligned}
$$

Thus, the threshold of precipitation intensity at which debris floods are triggered was obtained by other nondimensional variables using regression analyses based on Eq. (19.9):

$$
\frac{I}{g t}=F\left(\tan \theta, \frac{\sqrt{g} t}{\sqrt{d_{50}}}, \frac{\sqrt{g} t}{\sqrt{D}}, \frac{\sqrt{g} t}{\sqrt{L}}\right)
$$

\subsubsection{Experiment Procedures}

The average size of the sediments used in the laboratory tests was determined using the sieving method, and a sediment gradation curve was obtained (Fig. 19.2). According to Fig. 19.2, more than 90 percent of the sediments consisted of sand, and a small percentage of sediments were fine grains or coarse grains, such as clay and gravel. Thus, based on the ASHTO classification system (Zidan et al. 2019), the sediments were sandy-type with a mean grain size equal to $0.7 \mathrm{~mm}$. The laboratory test steps used to determine the precipitation intensity thresholds at which debris floods were initiation in the different sediment layer thicknesses and bed slopes were as follows.

I. The sediment weight was determined with the scale.

II. To consider the influence of moisture due to antecedent precipitation, a constant moisture content (5\% of the dry weight of the sediments) was added to the sediments.

III. The flume slope and camera were set.

IV. The rain simulator and its bases were prepared and placed on the flume. Then, the rain simulator reservoir was filled with water. Finally, the precipitation intensity was adjusted by calipers.

V. The instability of the slope of the particles was determined, and the sediment sample was transferred into the flume/channel. 
Fig. 19.2 Sediment gradation curve

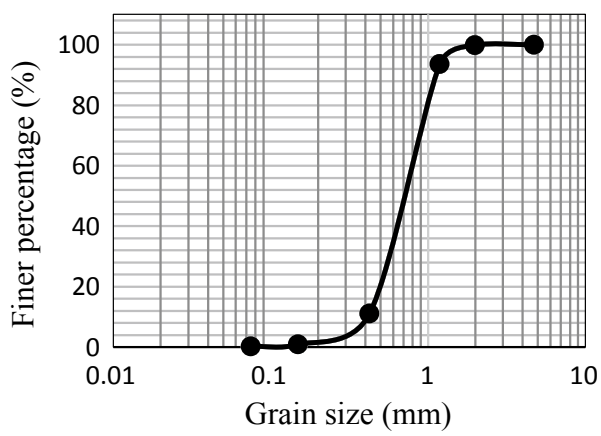

VI. The rain simulator was laid on its base, and raindrops were poured/fell over the sediments. Then, the time to the failure/collapse of the sediment sample was recorded using a camera.

For each sediment layer thickness, the laboratory tests were repeated a minimum of 7 times. In total, laboratory tests were carried out 57 times for diverse particle layer thicknesses and different bed slopes. This research examined debris floods that occurred on bedrock. For this reason, these experiments were performed using thin sediment layers (Banihabib and Tanhapour 2020).

\subsection{Results and Discussion}

Debris floods occur due to a set of climatic, topographic, and geological factors, and debris floods have complex relationships with the factors that affect them. Therefore, it is necessary to understand the conditions under which these floods occur and to determine the relations between debris floods and other related factors. Steep slopes, large volumes of loose deposits, and intense precipitation are essential for producing debris floods (Zhuang et al. 2015). To address the effects of these main criteria on debris flood initiation, a series of effective variables, including slope, depth of loose material, mean grain size, length of alluvial material in the flow direction, timing of the debris flood, and precipitation intensity at debris flood initiation, were selected. In this section, first, the influence of each dimensionless factor on the threshold of the precipitation intensity that triggers debris floods was investigated separately. Then, different methods for determining the precipitation intensity threshold of debris floods were examined. 


\subsubsection{Assessment of the Impacts of Dimensionless Variables on the Precipitation Intensity Threshold}

In this section, the impacts of dimensionless variables on debris flood occurrence were examined as a simple regression model. Figure 19.3 illustrates the simple nonlinear regression equation between $\Pi_{5}$ (the dimensionless precipitation intensity) and $\Pi_{2}$ (the dimensionless sediment mean diameter), and their good correlation was observed between them. Based on the observed results of the laboratory tests, a large volume of the soil texture was made up of fine sand particles. These particles are easily eroded by various precipitation intensities due to their negligible cohesion and relatively low weights, while the erosion rates of the coarse-grained particles and the clay materials are lower. This result is consistent with the results of other research (Vaezi and Ebadi 2016; Williams et al. 1997; Papa et al. 2004). Therefore, loose materials and fine sand particles provide suitable conditions for debris flood initiation, and there is a good relation between the precipitation intensity and this dimensionless factor.

Figure 19.4 demonstrates the nonlinear equation between the dimensionless precipitation intensity $\left(\Pi_{5}\right)$ and the dimensionless sediment layer thickness $\left(\Pi_{3}\right)$. Based on this figure, it is obvious that there is a fair correlation between these two factors. Generally, the precipitation intensity threshold increases with enhanced sediment layer thickness on a certain slope, which is mostly in agreement with the results of this research. For example, for thin sediment layers (between 1 and $2 \mathrm{~cm}$ ), the minimum precipitation intensity for debris flood initiation is $109 \mathrm{~mm} / \mathrm{h}$, while the required precipitation intensity increases to $153 \mathrm{~mm} / \mathrm{h}$ for thicker sediment layers (more than $2 \mathrm{~cm}$ ). It can be deduced that the sediment layer thickness alone is not sufficient to estimate the precipitation intensity threshold, and the sediment layer thickness alone cannot accurately estimate the precipitation intensity.

Figure 19.5 indicates the relationship between the dimensionless precipitation intensity $\left(\Pi_{5}\right)$ and the dimensionless factor $\Pi_{4}$. According to Fig. 19.5, there is

Fig. 19.3 Relation between $\Pi_{5}$ (the dimensionless precipitation intensity) and $\Pi_{2}$ (the dimensionless sediment mean diameter)

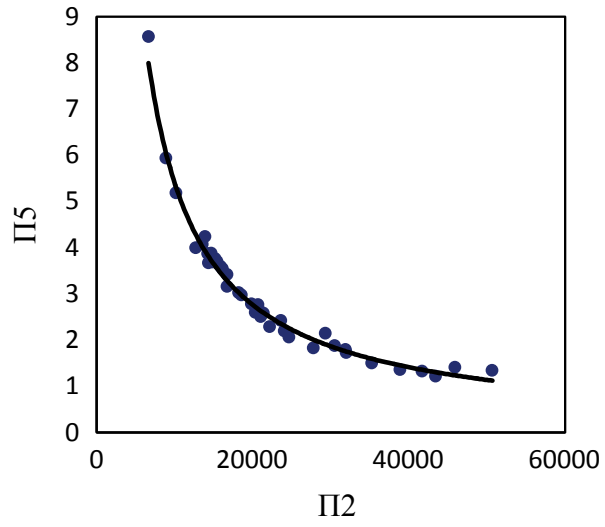


Fig. 19.4 Relation between the dimensionless precipitation intensity $\left(\Pi_{5}\right)$ and the dimensionless sediment layer thickness $\left(\Pi_{3}\right)$

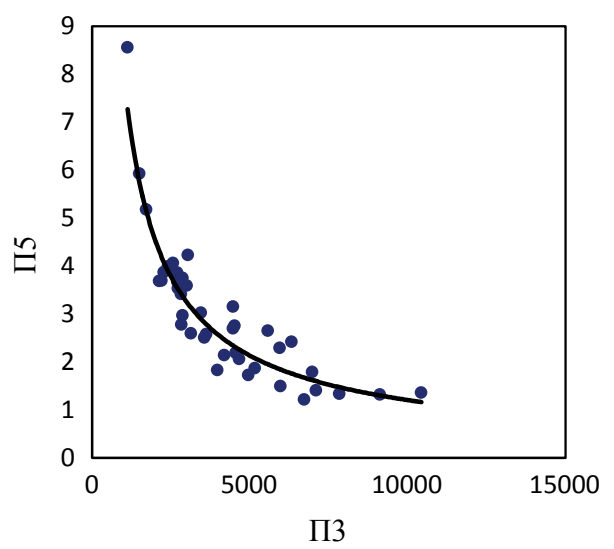

Fig. 19.5 Relation between the dimensionless precipitation intensity $\left(\Pi_{5}\right)$ and $\Pi_{4}$

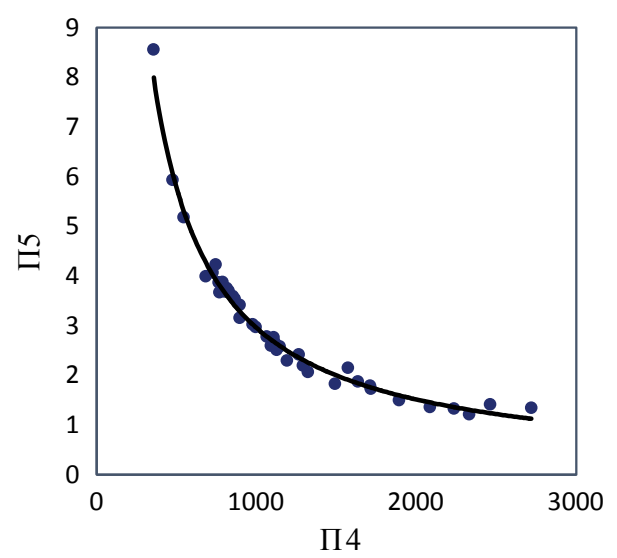

good consistency between the observed and estimated results, and the correlation between them is high. The value of the determination coefficient is 0.979 . Therefore, it can be inferred that there is a significant relation between the precipitation intensity threshold and sediment layer length.

Figure 19.6 shows the relation between the dimensionless precipitation intensity $\left(\Pi_{5}\right)$ and bed slope $\left(\Pi_{1}\right)$. The relation between these two factors is not significant. The results of this research revealed that precipitation intensity and bed slope are the main factors responsible for initiating debris floods, but the role of precipitation intensity on sediment layer failure is greater than the role of the bed slope. When the precipitation intensity increases, more runoff is produced, which leads to the destruction of the sediment layer and the initiation of debris floods. Therefore, by evaluating the relation between the roles of precipitation intensity and bed slope on debris flood initiation, it was found that precipitation intensity is more effective on the occurrence of debris floods than the bed slope is. 
Fig. 19.6 Relation between the dimensionless precipitation intensity $\left(\Pi_{5}\right)$ and bed slope $\left(\Pi_{1}\right)$

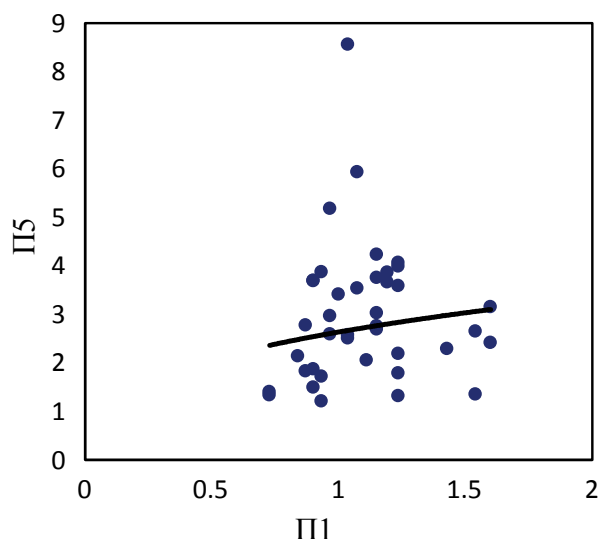

\subsubsection{Proposed Equation of This Study}

The derived equations in the previous section are shown in Table 19.2. More accurate results can be obtained based on the dimensionless sediment layer length and dimensionless sediment mean diameter (Eqs. (19.10) and (19.12)).

Since measuring the sediment mean diameter is easier than measuring the sediment layer length in practical uses, the relationship between $\Pi_{5}$ (the dimensionless precipitation intensity) and $\Pi_{2}$ (the dimensionless sediment mean diameter), represented by Eq. (19.10), is introduced as the proposed equation in this research. After rewriting, the equation is as follows:

$$
I=39482 g^{0.517} t^{0.034} d_{50}^{0.483}
$$

where $I$ is the precipitation intensity $(\mathrm{m} / \mathrm{s})$ and the other variables are introduced in Table 19.1. The unit of the precipitation intensity is $\mathrm{m} / \mathrm{s}$ in Eq. (19.10). Because the precipitation intensity is often expressed in millimeters/hour, its unit was changed to $\mathrm{mm} / \mathrm{h}$ in Eq. (19.15). Therefore, Eq. (19.10) was rewritten as Eq. (19.15):

$$
I=1421.3 g^{0.517} t^{0.034} d_{50}^{0.483}
$$

Table 19.2 Equations relating the dimensionless precipitation intensity and other dimensionless factors

\begin{tabular}{l|l|l|l}
\hline Number & Equation & $R^{2}$ & MARE \\
\hline 19.10 & $\frac{I}{g t}=39482\left(\frac{\sqrt{g} t}{\sqrt{d 50}}\right)^{-0.966}$ & 0.98 & 0.047 \\
\hline 19.11 & $\frac{I}{g t}=2387.5\left(\frac{\sqrt{g} t}{\sqrt{D}}\right)^{-0.824}$ & 0.83 & 0.163 \\
\hline 19.12 & $\frac{I}{g t}=2339.3\left(\frac{\sqrt{g} t}{\sqrt{L}}\right)^{-0.966}$ & 0.98 & 0.047 \\
\hline 19.13 & $\frac{I}{g t}=(\tan \theta)^{0.345}$ & 0.14 & 0.5
\end{tabular}




\subsubsection{Different Methods for Determining the Precipitation Intensity Threshold of Debris Floods}

Caine (1980) presented an intensity-duration threshold for shallow landslides and debris floods. He collected precipitation intensity-duration data that triggered landslides and debris floods in different areas worldwide. He utilized a series of 73 events to develop a global precipitation intensity-duration threshold equation. His proposed relationship is as follows:

$$
I=14.82 t^{-0.39} \quad(0.167 \leq t \leq 240)
$$

where $I$ and $t$ are the precipitation intensity $(\mathrm{mm} / \mathrm{h}$ ) and rainfall duration (h), respectively.

Cogan and Gratchev (2019) proposed an intensity-duration threshold for rainfall-induced landslides using a laboratory study. They carried out a series of 12 experiments to investigate the influences of the precipitation intensity and bed slope on triggering landslides and altered the bed slopes, precipitation intensities, and the amounts of initial moisture in the experiments. Flume experiments were performed for precipitation intensities equal to 40,70 , and $100 \mathrm{~mm} / \mathrm{h}$. According to the experiments, the slope angle and the amount of initial moisture were altered in the ranges of $45-55^{\circ}$ and $5-12 \%$, respectively. Then, the failure time was recorded in all experiments (Cogan and Gratchev 2019). Finally, the authors developed the intensity-duration threshold based on the observed landslides as follows:

$$
I=80.07 t^{-0.596} \quad(0.5 \leq t \leq 4)
$$

where $I$ and $t$ are the same as those introduced in the previous equation.

Zhuang et al. (2015) used 47 debris flood events to determine the intensityduration threshold in Jiangjia Gully, China. They employed past precipitation events to empirically derive the intensity-duration threshold and historical debris flood events to validate the threshold. They obtained 50, 70, and $90 \%$ probability thresholds to forecast debris flood events using the intensity-duration threshold. These probability curves include 50,70, and $90 \%$ of the debris flood event points. These probability thresholds can be employed to forecast debris flood occurrences and to alert the public about possible occurrences. The authors proposed the following thresholds for debris flood occurrence:

$$
\begin{array}{ll}
I=15.87 t^{-0.595} & (\text { for curve } 50 \%) \\
I=11.92 t^{-0.595} & (\text { for curve } 70 \%) \\
I=7.27 t^{-0.595} & (\text { for curve } 90 \%)
\end{array}
$$


Hirano (1997) proposed the system analysis method to obtain the concentration time $(T)$ and critical precipitation $\left(R_{c}\right)$ necessary for debris flood initiation. He determined the cumulative precipitation $R\left(t, t_{0}\right)$ as follows:

$$
R\left(t, t_{0}\right)=\int_{t-t_{0}}^{t} r(\tau) d \tau
$$

where $\tau$ is the shear stress and $t$ is the precipitation duration.

Based on this method, the maximum value of $R\left(t, t_{0}\right)$ for each rainfall duration was plotted versus $t_{0}$. According to Fig. 19.7, if there is no error present in the information or data, the lines should cross above point $R_{\max }(T)$ when debris floods occur (Fig. 19.7a) and should cross below point $R_{\max }(T)$ when debris floods do not occur (Fig. 19.7b).

The difference between the upper bound curve of the nonoccurrence plot and the lower bound curve of the occurrence plot is minimal at point $R_{\max }(T)$, which is shown in Fig. 19.8. Consequently, if the cumulative precipitation at the concentration time is greater than the upper bound curve of the nonoccurrence plot, debris floods occur. If the cumulative precipitation at the concentration time does not exceed the lower bound curve of the occurrence plot, debris floods do not occur. The distance between these two curves is a critical area for triggering debris floods (Fig. 19.8) (Hirano 1997).

Tanhapour and Banihabib (2019) investigated the cumulative rainfall thresholds based on Hirano's method (system analysis method) in the northern areas of the Alborz Mountains, Iran, including the Karganrud, Navrud, Neka, and Babolrud basins. They used rainfall data to derive cumulative rainfall thresholds and

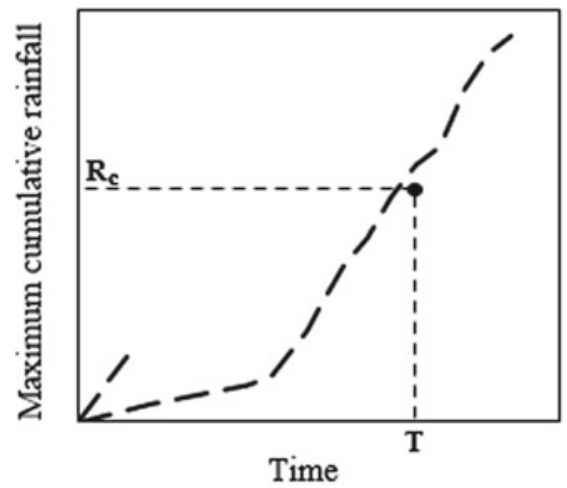

(a)

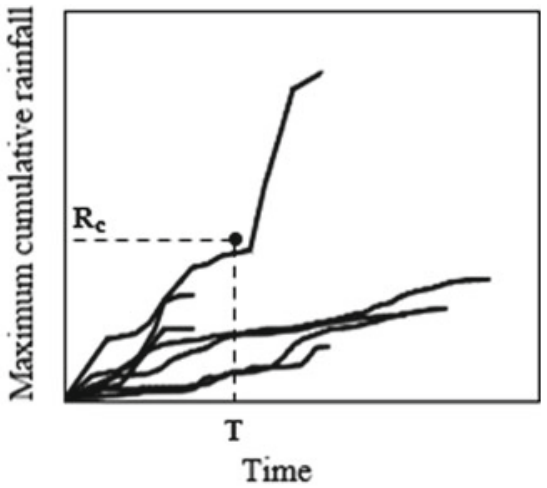

(b)

Fig. 19.7 Maximum cumulative precipitation against time for a debris flood occurrence and b nonoccurrence (Tanhapour and Banihabib 2019) 
Fig. 19.8 Lower bound of the occurrence curve and the upper bound of the nonoccurrence curve (Tanhapour and Banihabib 2019)

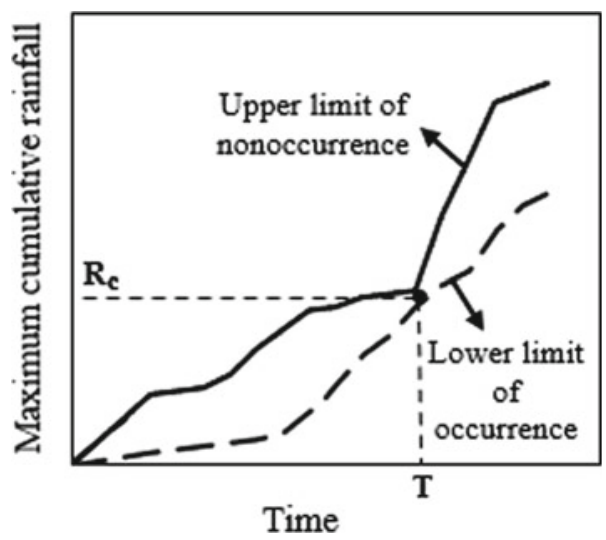

developed a regional intensity-duration threshold for debris flood occurrence (Tanhapour and Banihabib 2019). The threshold curve can be determined using Eq. (19.22):

$$
I=6.14 t^{-0.536} \quad(0.7 \leq t \leq 15)
$$

\subsubsection{Precipitation Threshold for Flash Floods}

In dealing with floods, early warning systems often need an indicator to detect flood events. Precipitation threshold-based methods and assessments of local soil moisture conditions for predicting debris floods and flash floods have long histories. Precipitation thresholds can be used to construct early warning systems for debris floods and flash floods (Bezak et al. 2016). Flash flood predictions depend on various factors, e.g., precipitation, soil moisture, water level, time of occurrence, flood duration, and flood peak time (Ngo et al. 2020). One of the simplest threshold-based approaches for predicting flash floods is to detect extreme weather conditions using weather parameter-based indicators, such as cumulative precipitation. Norbiato et al. (2008) revealed that the inclusion of the effect of initial soil moisture conditions in humid climates is important in assessing the potential of a flash flood occurrence and especially in determining the occurrence and nonoccurrence thresholds. Bezak et al. (2016) proposed intensity-duration-frequency curves and precipitation thresholds for flash floods and landslides.

The usage of simple threshold-based approaches is crucial for several reasons. These thresholds can be applied by flood risk managers in local flood prediction centers. Consequently, communities' preparation levels against floods can be increased. In addition, precipitation threshold-based diagnostic methods and soil moisture indices, which simplify the hydrological status of catchments, provide the possibility of processing local precipitation information and promoting cooperation 
between hydrologists and meteorologists (Borga et al. 2014). One of the most important problems associated with this approach (the precipitation threshold approach) is that the false warning ratio is high, which is due to uncertainties in the spatial distributions of rainfall and errors in the precipitation thresholds (Bezak et al. 2016). In this study, a laboratory method was developed to determine the threshold at which debris floods occur, and different approaches used in previous studies were evaluated to determine the rainfall threshold for debris flood occurrences. Depending on the local precipitation characteristics and the physiographic characteristics of the basins, flash floods can lead to debris floods. Generally, determining the precipitation threshold along with a sufficient number of rain gauge stations can be used as part of an early warning system to alert users to the occurrence of flash floods and debris floods.

\subsubsection{Comparing the Proposed Equation with the Equations from Previous Studies}

In this study, we used 40 debris flood events (70\% of all data) to fit the empirical equations and 17 debris flood events (30\% of all data) to test the equations. The previous studies' equations describing the precipitation intensity threshold were compared with the equation proposed in this study (Eq. (19.15)) using the laboratory test data displayed in Table 19.3. It was thus found that the MARE coefficients for the equations proposed by Cogan and Gratchev (2019), Tanhapour and Banihabib (2019), Caine (1980), and Zhuang et al. (2015) were 1.86, 0.81, 0.71, and 0.43 , respectively, while is the MARE coefficient was equal to 0.047 for the equation proposed in this research. Thus, the equation proposed in this study is better than the equations of previous studies, and the equation proposed here can more accurately estimate the precipitation intensity threshold at which debris floods are generated.

Table 19.3 Precipitation intensity thresholds from other studies with that obtained in this research

\begin{tabular}{l|l|l|l}
\hline Study & Study area & MARE & Equation \\
\hline Zhuang et al. (2015) & China & 0.43 & $I=15.87 t^{-0.595}$ \\
\hline Caine (1980) & Global & 0.71 & $I=14.82 t^{-0.39}$ \\
\hline $\begin{array}{l}\text { Tanhapour and } \\
\text { Banihabib (2019) }\end{array}$ & $\begin{array}{l}\text { Northern areas of the } \\
\text { Alborz Mountains }\end{array}$ & 0.81 & $I=6.14 t^{-0.536}$ \\
\hline $\begin{array}{l}\text { Cogan and Gratchev } \\
(2019)\end{array}$ & $\begin{array}{l}\text { Based on observed } \\
\text { landslides }\end{array}$ & 1.86 & $I=80.07 t^{-0.596}$ \\
\hline This study & $\begin{array}{l}\text { Based on observed debris } \\
\text { floods }\end{array}$ & 0.044 & $I=1421.3 g^{0.517} t^{0.034} d_{50}^{0.483}$ \\
\hline
\end{tabular}




\subsection{Conclusion}

In the current study, a laboratory model was employed to determine the precipitation intensity threshold at which debris floods occur using a set of factors, including sediment layer thickness, bed slope, grain mean diameter, length of sediment, precipitation intensity, and time of debris flood occurrence. Furthermore, the equation developed in this study was compared with equations obtained in former studies. To obtain the precipitation threshold at which debris floods are produced, dimensional analysis was applied, and the influences of various dimensionless factors on the precipitation intensity threshold were assessed separately. It was found that dimensionless sediment length and dimensionless sediment mean diameter were the most influential factors on the precipitation intensity threshold, while the influence of the dimensionless sediment layer thickness was the lowest. The results revealed that the equation proposed in this study can be used to estimate the precipitation intensity threshold more accurately than the equations of previous studies. The findings of this study can be used for identifying precipitation intensities that produce debris floods and designing warning systems for debris floods.

\section{References}

Ashley ST, Ashley WS (2008) Flood fatalities in the United States. J Appl Meteorol Climatol 47 (3):805-818

Banihabib ME, Masumi A (1999) Effect of high-concentrated sediment transport on inundation of rivers: case study Masuleh Flood. Chapter presented at the 2nd Iranian Hydraulic Conference, Iranian Hydraulic Association, Tehran, Iran

Banihabib ME, Forghani A (2017) An assessment framework for the mitigation effects of check dams on debris flow. CATENA 152:277-284

Banihabib ME, Nazarieh F (2019) A model for simulation of debris flow sedimentation in slit detention-dam reservoirs. J Hydro-Environ Res 27:65-74

Banihabib ME, Tanhapour M (2019) Proposing an empirical equation for estimation of the sediment concentration of debris Flow (Case Study: Jiangjia Gully in China). Iran J Watershed Manag Res 9(18):70-79

Banihabib ME, Tanhapour M (2020) An empirical equation to determine the threshold for rainfall-induced landslides developing to debris flows. Landslides 17:2055-2065

Banihabib ME, Tanhapour M, Roozbahani A (2020) Bayesian networks model for identification of the effective variables in the forecasting of debris flows occurrence. Environ Earth Sci 79:179. https://doi.org/10.1007/s12665-020-08911-w

Barredo JI (2007) Major flood disasters in Europe: 1950-2005. Nat Hazards 42(1):125-148

Berger C, McArdell BW, Schlunegger F (2011) Sediment transfer patterns at the Illgraben catchment, Switzerland: implications for the time scales of debris flow activities. Geomorphology 125(3):421-432

Bezak N, Šraj M, Mikoš M (2016) Copula-based IDF curves and empirical rainfall thresholds for flash floods and rainfall-induced landslides. J Hydrol 541:272-284

Borga M, Stoffel M, Marchi L, Marra F, Jakob M (2014) Hydrogeomorphic response to extreme rainfall in headwater systems: flash floods and debris flows. J Hydrol 518:194-205

Caine N (1980) The rainfall intensity-duration control of shallow landslides and debris flows. Geogr Ann Ser B 62(1-2):23-27 
Chang TC, Wang ZY, Chien YH (2010) Hazard assessment model for debris flow prediction. Environ Earth Sci 60(8):1619-1630

Cogan J, Gratchev I (2019) A study on the effect of rainfall and slope characteristics on landslide initiation by means of flume tests. Landslides 16(12):2369-2379

Coussot P, Meunier M (1996) Recognition, classification and mechanical description of debris flows. Earth Sci Rev 40(3-4):209-227

Diakakis M, Deligiannakis G (2017) Flood fatalities in Greece: 1970-2010. J Flood Risk Manag 10(1):115-123

Diakakis M, Deligiannakis G, Antoniadis Z, Melaki M, Katsetsiadou NK, Andreadakis E, ... Gogou M (2020) Proposal of a flash flood impact severity scale for the classification and mapping of flash flood impacts. J Hydrol 590:125452

Dong JJ, Lee CT, Tung YH, Liu CN, Lin KP, Lee JF (2009) The role of the sediment budget in understanding debris flow susceptibility. Earth Surf Proc Land 34(12):1612-1624

Egashira S (1993) Mechanism of sediment deposition from debris flow (part 1). J Jpn Soc Erosion Control Eng 46(1):186

Evans SG, Hungr O, Clague JJ (2001) Dynamics of the 1984 rock avalanche and associated distal debris flow on Mount Cayley, British Columbia, Canada; implications for landslide hazard assessment on dissected volcanoes. Eng Geol 61(1):29-51

Hassan-Esfahani L, Banihabib ME (2016) The impact of slit and detention dams on debris flow control using GSTARS 3.0. Environ Earth Sci 75(4):328

He B, Huang X, Ma M, Chang Q, Tu Y, Li Q, Hong Y (2018a) Analysis of flash flood disaster characteristics in China from 2011 to 2015. Nat Hazards 90(1):407-420

He S, Wang D, Chang S, Fang Y, Lan H (2018b) Effects of the morphology of sediment-transporting channels on the erosion and deposition of debris flows. Environ Earth Sci 77(14):544

Hirano M (1997) Prediction of debris flow for warning and evacuation. In: Recent developments on debris flows. Springer, Berlin, Heidelberg, pp 7-26

Hu W, Xu Q, van Asch TWJ, Zhu X, Xu QQ (2014) Flume tests to study the initiation of huge debris flows after the Wenchuan earthquake in SW China. Eng Geol 182:121-129

Iverson RM, Denlinger RP (2001) Flow of variably fluidized granular masses across threedimensional terrain: 1. Coulomb mixture theory. J Geophys Res Solid Earth 106(B1):537-552

Jomelli V, Pavlova I, Eckert N, Grancher D, Brunstein D (2015) A new hierarchical Bayesian approach to analyse environmental and climatic influences on debris flow occurrence. Geomorphology 250:407-421

Kotlyakov VM, Desinov LV, Dolgov SV, Koronkevich NI, Likhacheva EA, Makkaveev AN, ... Rudakov VA (2013) Flooding of July 6-7, 2012, in the town of Krymsk. Reg Res Russ 3 (1):32-39

Liang WJ, Zhuang DF, Jiang D, Pan JJ, Ren HY (2012) Assessment of debris flow hazards using a Bayesian Network. Geomorphology 171:94-100

Mangeney A, Roche O, Hungr O, Mangold N, Faccanoni G, Lucas A (2010) Erosion and mobility in granular collapse over sloping beds. J Geophys Res Earth Surf 115(F3):1-21

Ngo TTH, Vu BT, Nguyen TK (2020) Early warning systems for flash floods and debris flows in Vietnam: a review. Geotechnics for sustainable infrastructure development. Springer, Singapore, pp 1233-1240

Norbiato D, Borga M, Degli Esposti S, Gaume E, Anquetin S (2008) Flash flood warning based on rainfall thresholds and soil moisture conditions: An assessment for gauged and ungauged basins. J Hydrol 362(3-4):274-290

Papa M, Egashira S, Itoh T (2004) Critical conditions of bed sediment entrainment due to debris flow. Nat Hazard Earth Syst Sci 4:469-474

Pellegrino AM, Schippa L (2018) A laboratory experience on the effect of grains concentration and coarse sediment on the rheology of natural debris-flows. Environ Earth Sci 77(22):749

Procter C (2012) Debris flow dynamics: a flume study of velocity and super elevation, Doctoral dissertation, Durham University 
Salvati P, Bianchi C, Rossi M, Guzzetti F (2010) Societal landslide and flood risk in Italy. Nat Hazard 10(3):465-483

Shu AP, Wang L, Zhang X, Ou GQ, Wang S (2017) Study on the formation and initial transport for non-homogeneous debris flow. Water 9(4):253

Sun D, Zhang D, Cheng X (2012) Framework of national non-structural measures for flash flood disaster prevention in China. Water 4(1):272-282

Takahashi T (1977) A mechanism of occurrence of mud-debris flows and their characteristics in motion. Annu Disaster Prev Res Inst 20:405-435

Takahashi T (1981) Debris Flow. Annu Rev Fluid Mech 13:57-77

Takahashi T, Kuang SF (1986) Formation of debris flow on varied slope bed. Disaster Prev Res Inst Annu 29:345-349

Tanhapour M, Banihabib M (2019) Determination of the rainfall threshold for debris flow occurrence in a part of Alborz mountainous basins. J Watershed Eng Manag 11(3):575-588

Tanhapour M, Banihabib ME, Rouzbahani A (2018) Bayesian network model for the assessment of the effect of antecedent rainfall on debris flow forecasting in Alborz zone of Iran. Iran Water Res Res 13:118-131

Vaezi AR, Ebadi M (2016) Particle size distribution of surface-eroded soil in different rainfall intensities and slope gradients. J Water Soil 31(1):216-229

Williams JJ, Rose CP, Thorne PD, Coates LE, West JR, Harcastle PJ, ... Wilson DJ (1997) Observed suspended sediments in storm conditions. Coast Eng Proc 3257-3269

Zhuang J, Cui P, Wang G, Chen X, Iqbal J, Guo X (2015) Rainfall thresholds for the occurrence of debris flows in the Jiangjia Gully, Yunnan Province, China. Eng Geol 195:335-346

Zidan AF, Aboukhadra AA, Gaber Y (2019) Enhancement of resilient modulus of cohesive soil using an enzymatic preparation. J Central South Univ 26(9):2596-2608

Open Access This chapter is licensed under the terms of the Creative Commons Attribution 4.0 International License (http://creativecommons.org/licenses/by/4.0/), which permits use, sharing, adaptation, distribution and reproduction in any medium or format, as long as you give appropriate credit to the original author(s) and the source, provide a link to the Creative Commons license and indicate if changes were made.

The images or other third party material in this chapter are included in the chapter's Creative Commons license, unless indicated otherwise in a credit line to the material. If material is not included in the chapter's Creative Commons license and your intended use is not permitted by statutory regulation or exceeds the permitted use, you will need to obtain permission directly from the copyright holder. 